\title{
Waste, Management and Energy: An Adhesion
}

\author{
Gabriela lonescu* \\ Department of Civil, Environmental and Mechanical Engineering, University of Trento, via Mesiano 77, 38123, Italy
}

The current status of enhanced waste management embraces many options such as pyrolysis, gasification and incineration that are able to convert the waste in by-products. Due to the nature of raw materials and conversion mechanisms used, the quality of the by-products differs considerably. Therefore these factors should justify the waste thermal conversion analysis, in the context of environmental and economic benefits.

Today the incineration is the most throughout form of wasteto-energy (WtE) valorification. Overlooking the waste incineration plants hierarchy, the technology is mostly applied in: Europe (Belgium, Denmark, Germany, France and the Netherlands), North America, Japan and South Korea. By international comparison, USA and China have very large incineration capacity, due their higher population.

Modern gasification technologies offer an alternative process that devolatilizes hydrocarbons which are reformed into quality synthetic gas. Uses of syngas for power, chemicals and methanol production and flexibility of gas clean-up technologies make gasification a suitable process for WtE. By comparison with incineration which has benefits from the technological simplicity point of view, the gasification minimizes the pollutant emissions. According to the US Department of Energy's (DOE) 2010 Worldwide Gasification Database and looking over the continental distribution by operating capacity, the leading region is Africa/ Middle East with 37\% due the rapid growth in Qatar, followed by Asia/Australia with 36\%. Still European region (16\%) remains the third largest region; succeed by North America (10\%) and Central/South America (1\%).

In the last few decades the tendency of using the pyrolysis process at large scale applications has gained more and more field. This treatment is applied to different feedstock to produce differing end products. The pyrolysis and gasification of homogenized waste is used all over the world, particularly in Japan and parts of Europe and Scandinavia.

Even though these technologies offer a sustainable WtE solution, there are some question marks related to their development, application and integration in any waste management system. The starting point is defined by two main critical waste characteristics: quantity and quality. The selective collection stage influences the later parameters. Without doubt the economic aspect represents the key. If we consider the best available technologies on the market, the technological impediments usually come from the above mentioned. Also, the legislation and different polices usually delay and constrain the quick integration of the WtE plant in the system. A detailed waste management study should consider all these criteria leading to reliable information for the development of a sustainable project.

Summing up, the current challenges for the implementation of a WtE project can be visualized in Figure 1. The merge of these criteria, combined with an efficient waste management and energy production/ generation adhesion, can assure a long-term stable source of energy, environmental friendly solution and moving financial market.

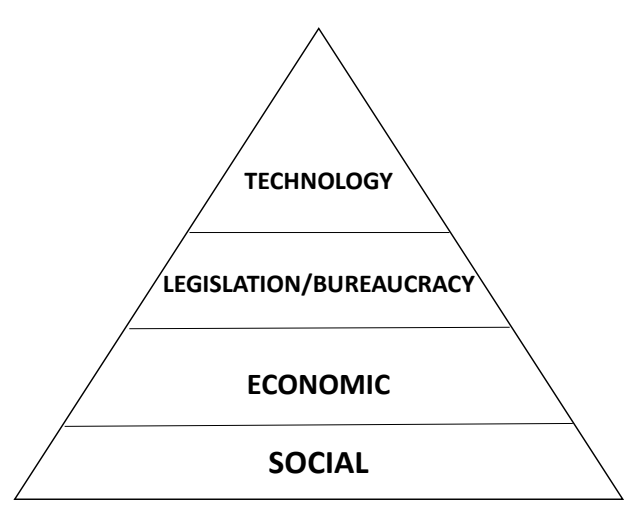

Figure 1: Current challenges of large WtE projects integration in a waste management system.
*Corresponding author: Gabriela lonescu, Department of Civil, Environmental and Mechanical Engineering, University of Trento, via Mesiano 77, 38123, Italy, Tel: +39 0461282605 ; E-mail: Gabriela.Ionescu@unitn.it

Received November 29, 2013; Accepted November 29, 2013; Published December 05, 2013

Citation: Ionescu G (2013) Waste, Management and Energy: An Adhesion. Int J Waste Resources 3: e104. doi: 10.4172/2252-5211.1000e104

Copyright: (c) 2013 lonescu G. This is an open-access article distributed under the terms of the Creative Commons Attribution License, which permits unrestricted use, distribution, and reproduction in any medium, provided the original author and source are credited. 